\title{
Giorgio Piccardi: A Forgotten, But Great, Italian Scientist
}

\author{
Carlo Artemi \\ Public Education Department, High School Fabio Besta, Orte, Italy
}

\section{Email address:}

carloartemi@gmail.com

\section{To cite this article:}

Carlo Artemi. Giorgio Piccardi: A Forgotten, But Great, Italian Scientist. History Research. Vol. 3, No. 2, 2015, pp. 25-34. doi: 10.11648/j.history.20150302.12

\begin{abstract}
Professor Giorgio Piccardi was one of the most controversial and significant Italian scientists of the 50s and 60s. He was University Professor of Chemistry and Physics at Florence University and Director of the Chemistry and Physics Department. He was a very acculturated man (also in the humanities); he was an ante litteram environmentalist and an elegant and refined man. He did research in many fields (outside Chemistry too), publishing dozens of books and scientific articles, many of them in English and Deutsch He was the first in Italy to investigate surface phenomena. He taught people who would make remarkable things. He was always interested in multidisciplinary research and tried steadily to encourage the cooperation of scholars in disciplines different from his. He claimed to have discovered an effect (the Piccardi effect) in which interplanetary magnetic fields influenced the result of some simple inorganic reactions and, in general, the results of non-reproducible phenomena (fluctuating phenomena). It was believed, and it is still generally believed, that the Piccardi effect is a self-deceptive result, but this does not diminish the importance of Piccardi as a scientist, teacher and man. This article will trace Piccardi's life, focusing in particular on its effect and on its popularization, characterized by mistakes made both by supporters and detractors. The author will show an original contributions of his regarding the Piccardi effect's explanation, one more complete than the present one in the scientific community, and its use in teaching. The article concludes with considerations regarding the scientific and human legacy of Piccardi and on how a figure like him can contribute to working in science today.
\end{abstract}

Keywords: History of Physics, Fluctuating Phenomena, Italian Scientists, Piccardi Effect, Self-deceptione

\section{Early Career}

Professor Giorgio Piccardi [1] (Florence, October 13, 1895Riccione, December 22, 1972) was one of the most controversial Italian scholars of the twentieth century. Piccardi enrolled in 1913 at the Institute of Higher Studies and Practical Improvement of Florence, where he was a pupil of Ugo Schiff, a German chemist [2] and naturalized Italian who made important discoveries in organic chemistry. Piccardi interrupted his studies due to the outbreak of World War I, in which he was an official in the "Alpini”" (an Italian corps of mountain infantry). He received a silver medal and took it back at the end of the conflict to the faculty of chemical engineering at the Politecnico di Torino. Finally, he returned to Florence and graduated with Luigi Rolla in 1922. After graduation, he worked for many years at the University of Florence as a volunteer without pay until 1938. The first phase of Piccardi's academic life was marked by several papers on spectroscopy and in particular on the spectroscopy of rare earth [3].These works were fully in keeping with the scientific evolution of those years. In the 20s, Schrondinger and Heisenberg's work on the foundations of quantum mechanics and later models such as the Fermi-Thomas model (that made possible to apply the same quantum mechanics to many electrons atoms) allowed predicting the spectral properties of elements with many electrons and then became very interesting making their accurate experimental verification. In fact, the first theoretical works by Ettore Majorana related to atomic and molecular spectroscopy too [4]. This phase of Piccardi's activity is documented by 71 published papers including two conference communications. All are in Italian, except for two that are in German, five in English and one in French. Most of these works were written between 1925 and 1942.

If these works are analyzed they show already some particular features of the scientist and the man Piccardi. First, there is the inclination to do research involving scientists from different disciplines, in particular those with an interest in astrophysics. Some jobs involve a spectroscopic examination of the solar atmosphere. In particular, in [5], Piccardi speaks about an analysis conducted on a photo taken at Arcetri Solar Tower, which showed, in the part corresponding to a sunspot, lines virtually absent outside of the stain. Piccardi speculated that these lines could be molecular hydrogen lines and quoted the checks 
made by him on the spectra of the same Sun area taken by the Mount Wilson telescope.It's to note that, during the performance of the research, Piccardi met the famous astrophysicist Guglielmo Righini. A scientific collaboration and human closeness that would last for decades was the result of this encounter. In addition, Piccardi paid particular attention to research that went beyond the field of physics, not neglecting even the humanities. In the paper [6], written in collaboration with a pediatrician, Piccardi reported a series of measures of the surface tension of breast milk secretion in a time interval of about 20 minutes. To explain the observed variations, Piccardi formulated both a standard explanation based on the behavior of the surfactant present in milk and a more exotic one based on the assumption that breast milk contained a lively and vital component interacting in some way with the physiology of the newborn. In the paper [7], Piccardi gave a demonstration of his attention to all areas of culture, but this work will be discussed at the end of the article. However, this intensive research work had a downside. Piccardi and co-workers claimed to have discovered a new chemical element, a rare earth that they called fiorenzio [8], but further investigatiosn revealed that it was a mistake. This was a period of claims of discoveries of new elements, for example, the transuranic elements ausonio and esperio whose discovery was announced by the Fermi group in 1934 (Fermi received the Nobel Prize for physics in 1938 for this discovery) and the announcement of the discovery of element 42 masurium by Ida Noddack [9]. This last claim was taken very seriously, so that, in a popular book written by Gamow in 1950 [10], masurium was explicitly shown in the periodic table. In 1938, Piccardi won a competition for a professorship at Genova University and, at that time [11], began his attention to the so-called floating phenomena that would take him to the controversial discovery of the effect which bears his name. The outbreak of World War II prevented him from continuing his research. Among other things, he found himself in the south of the Gothic Line and, not being able to reach Genova, he started to work at the University of Florence where he would transfer after the war in 1948, becoming Director of the Department of Chemical Physics of the university. Here, he started to study the fluctuating phenomena again.

\section{Floating Phenomena}

Towards the end of the 30 s, during research on the formation of limescale deposits on pipes carrying water, Piccardi was aware of a strange phenomenon or rather he heard a strange "rumor." It was said that if a bulb filled with neon was shaken inside of a tube containing water, deposits decreased, but the effect was not deterministic; it was only statistical. Piccardi speculated that the shaking of the bulb would generate radio waves by triboelectricity [12] and that these had no effect on the substances the water melted but had an effect on the water itself, and that this effect would bring the reduction of fouling. After the war, he resumed his studies on phenomena of this kind, which he called "fluctuating phenomena" for their unpredictability. This field of research would occupy him until his death in 1972 and virtually all of his scientific production, which included more than 200 papers among journal articles, books and conference communications, including 10 papers in German, nine in French and 20 in English. Studying these phenomena, Piccardi immediately suspected that their randomness was not due to errors or to malpractice of the experimenters but was due to the effects that external factors have on the system. These external factors may be climatic, environmental or even extraterrestrial. More precisely, Piccardi's idea was that water properly "activated" by low-frequency electromagnetic waves becomes sensitive to environmental factors such a way to change some feature of it. Piccardi then tried a simple and reproducible phenomenon to be able to test this idea and selected the chemical reaction in which the precipitation of chloride bismuth in water producing ossicloride bismuth. The sedimentation rate was not constant, and the form of the precipitate varied randomly too. Sometimes the precipitate was dusty, and other times it was in granules. Piccardi therefore devised a test, which became known as the Piccardi test [13]. Several wide and shallow (so that the precipitate is deposited only on the bottom) test tubes were filled with water. Half of these were exposed to "electric actions" [14] in order to activate the water. Every tube was put in a mechanical device called a synchronous mixer. This device is described in [15] and is schematically shown in the figure. Metallic screen $\mathrm{S}$ screened half of the tubes by the action of local electromagnetic fields, and it was not always used. Below were tubes filled with water, some of these with non treated water (the mutual arrangement is not clear, but, probably, pipes with treated water and with normal water were interspersed). Above. there were tubes containing chloride. Obviously the tops of these could be redressed to pour the chloride in the water. In this way, the water-chloride mix was absolutely uniform.

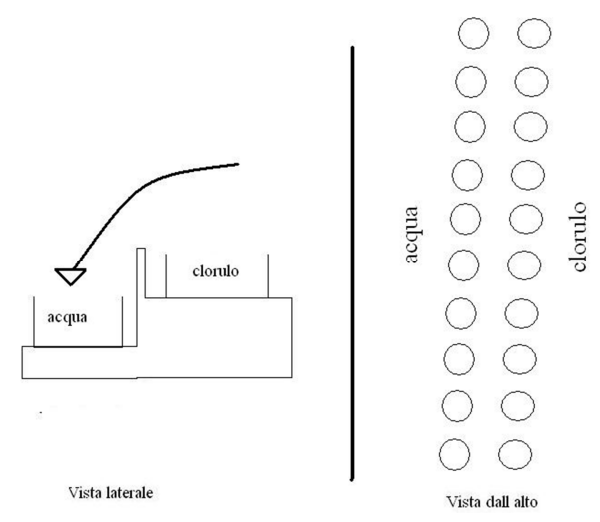

Fig. 1. A schematic vision of "Piccardi mixer".

The experimenter made a qualitative assessment to see if the precipitation rate was higher in the "activated water." It should be noted that this assessment was not interpreted as a measure but as 10 contemporary measures, there being10 pairs of tubes. Every day, a large number (some staff speak about more than 30 measures, but it is likely that it was three measurements per day [16]) of these tests was done using the mixer, and, at the end of the day, the ratio between the times in which there was an increase and the total number of trials was calculated. Time variation over long periods (even decades) of this ratio was studied to highlight the periodicity. There were different variants of this test. The D (in) test was carried out in a room that had been 
converted into a Faraday cage in order to eliminate the influences of local electromagnetic fields. The F tests (outside), however, were those made in normal rooms. The $\mathrm{P}$ tests were those in which only some of the tubes were shielded The important thing, that was much discussed and controversial, was that the tests were not quantitative measures but qualitative assessments, this according to Piccardi's faith, who more than once said "Gli scienziati devono pensare di più e pesare di meno Scientists must weigh less and think more." It could be answered to Piccardi that to "think" is typical of philosophers while to "weigh" is very typical of scientists, but this faith was a constant in Piccardi's modus operandi, as demonstrated by his thinking on the change in the surface tension of activated water [17]. Some of Piccardi's aides noticed that, touching the surface of the activated water, the water felt different from the touch of the non activated water. This observation led him to make measurements of surface tension. No difference was found, but he continued to think that water activation affected the surface tension itself. Another critical remark that could be made regarding Piccardi's work is that, if a measure was interpreted as 10 simultaneous measurements since there was only one observer, there was a difficulty in making assessments as there was also a 10-times higher chance of a mistake. Then, in the way of working of the Piccardi group, there was the strange coexistence of precision and inaccuracy. On one side, Becker tubes instead of normal tubes were used to make the precipitation of ossiclorulo only in the bottom and not also on the walls [18]. On the other side, in group's papers, there were graphics without any experimental points, only with an interpolation curve [19], and it is not even clear if they worked with tap water, demineralized water or distilled water. On the kind of water used, it is enough to say that Gianfranco Masini, a co-worker, friend and pupil of Piccardi, in telling of [20] measurements made by him on the Piccardi effect in an observatory in Norway, claims to have brought a synchronous mixer and ossiclorulo, but he says nothing about water, as if, in his measures, he had used tap water since it is difficult to think that in an astronomical observatory there is a large amount of distilled water. Returning to Piccardi's interpretation of test results in the beginning of the $50 \mathrm{~s}$, he saw or thought to see time periodicities in the above mentioned ratios (the Piccardi effect) and, in the mid-50s [21], formulated a bold hypothesis to explain the same periodicity, the solar hypothesis.

\section{Astrochemistry}

As can be seen in Fig. 2 taken from [14], Piccardi and staff were confident to have identified two time periodicities in the values of the ratio, more precisely, an annual and an 11-year periodicity. Piccardi had the idea to connect these intervals to astrophysical phenomena as the Earth's revolution relative to the Sun and the sunspot cycle. So, Piccardi hypothesized that changes in that were called interplanetary magnetic fields (today the solar magnetic field) influenced the capacity of water to react with bismuth chloride when water was activated. The Piccardi group was never able to formulate a viable theoretical explanation for this phenomenon, but the main idea was that the action of low frequency electromagnetic radiation modified the hydrogen bonds [22] between the water molecules such a way to create a certain "structure of water." This concept was taken up by supporters of homoeopathy in the 80 s [23]. Instead, professor Giao [24] thought of a relativistic effect. Once created, these structures were able to feel, as if they were antennae, interplanetary magnetic fields. The solar hypothesis was later formalized, taking into account the motion of the Sun through the Galaxy, and, therefore, also taking into account the galactic magnetic field in the so-called "dynamic model" [25]. In this model, it is assumed that Earth is travelling along a helical trajectory with respect to the total galactic magnetic field resulting from the sum of the Earth's revolution around the Sun and the Sun's motion with respect to the constellation Hercules.

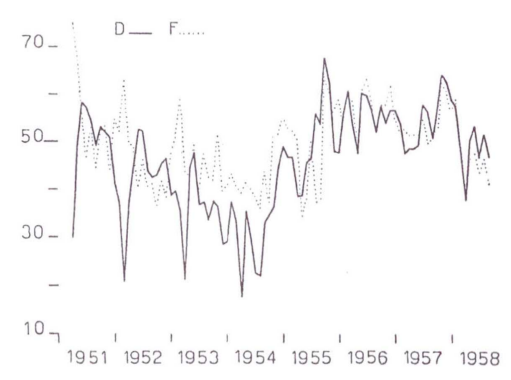

Fig. 2. Time variation od Piccardi test results

This hypothesis was revolutionary and some interpretations [26] accentuated this character perhaps even beyond Piccardi's intentions. In fact, some scholars postulated that the Piccardi effect, and more generally the existence of fluctuating phenomena, raised doubts regarding the repeatability of experiments and transformed time into a real coordinate of physical processes. For example, if the result of some experiments depends on low intensity variable effects such as the solar magnetic field, then how could one be sure that an experiment could be reproduced in the same conditions? In fact, this position was contradictory because the same discovery of the Piccardi effect showed that such influences could be discovered, if real, and, therefore, even if they could not be deleted, they could be taken into account in assessing the results of the experiment. We will come back later to those who have called into question the Piccardi effect in terms of homoeopathy and astrology. Once the solar hypothesis was formulated, Piccardi tried to contact colleagues, having many international contacts, to find confirmations of his hypothesis and to create collaborations. The results of these efforts were diverse and contradictory. At the local level, i.e., at Florence University, he soon found students and staff willing to work with him, and these people became the advisers of his discoveries. Among them was Professor Ferroni, later director of the Department of Chemistry of the university and Chancellor of the university itself, and the well-known popularizer and journalist, as well as chemical, Gianfranco Masini, whom we will speak about. Speaking about his closest collaborators, it has to be mentioned that Piccardi had a great ascendancy over them due to his human qualities recognized by all [27]. Piccardi was an elegant, cultured and educated man. He was a great storyteller who never got angry. He was a nature lover and environmentalist before his time and very courteous and 
respectful of women, whose professionalism he appreciated. Piccardi was very open to students too; he was really admired by colleagues and co-workers to the point that many of them were willing to work on his research even in the absence of economic returns. These features fueled the strong envy of other academic towards him. Academic envy was amplified by the "bossy" structure of the Italian university, the same bossy structure that has also been recently reported by several sources [28] [29] and contributed to situations investigated many times by the judiciary. Piccardi also found the collaboration of astrophysicist Righini (he worked in Florence too in the Arcetri Observatory where he was the Director) who helped him in an observation campaign of the tests conducted by Masini at the astronomical observatory of Tromsoe in Norway [30], which seemed to confirm the reality of the Piccardi effect. But in the remaining part of the Italian academic environment, Piccardi found, also for the reasons mentioned above, indifference, hostility and coldness towards his discovery, so much so that, outside of Florence, no other Italian scientific institute worked with him, and, as evidenced by his own co-workers [31], his funding requests to the national organizations for scientific researches were rejected in a systematic way. This negative attitude was justified by the above-mentioned defects of the experimental methodology of Piccardi and also by the lack of a viable theoretical explanation of the same. It should also be noted that research done since the $60 \mathrm{~s}$ [32] on a possible structure of liquid water has actually detected structures, or combinations of molecules, but they are stable structures for only very short periods, far shorter than the time required for the reactions studied by Piccardi. Despite this, all work submitted for publication by Piccardi was also regularly published in prestigious journals such as Nature or Algemai Chimie. Moreover, no experiment to test the Piccardi effect was ever realized in Italy. But Piccardi always tried collaboration, as you can see from any of his biographies. He gained attention in the international field by finding the active collaboration, that lasted from 1948 to his death, of the Belgian engineer Capel Boute who, among other things, effected, from 1956 to 1976 , measures similar to those of Piccardi in Brussels and found similar results. The international scientific community, in the absence of any hostility, welcomed the claims of Piccardi with indifference, as can be seen from any literature search. For example, if one looks at database www.arXiv.org, one would see very few if any citations of this effect. It is due to the above criticisms, criticisms which were formalized in 1986 by Kauffman [33] in article that I could not read but which is summarized in [17]. In practice, the fundamental criticism of Kaufman and others is this; Piccardi made rigorous statistical tests not on quantitative measures but on qualitative estimates made by people believing in the Piccardi effect and operating according to an inaccurate experimental protocol. There was a situation similar to that in which N-rays were discovered, a discovery revealed later as fallacious. Accordingly, the Piccardi effect is not a real effect but, an effect of self-deception in which the experimenter "sees" or thinks he sees what he believes.

One contribution of mine to the study of the Piccardi effect,on which we will return, confirms, though with a few caveats, that is affirmed by Kauffman. Besides, it seems [34] measures carried out by researchers at NCAR that were more accurate than Piccardi's, did not return any results. However, Piccardi managed to squeeze collaborations or at least friendly contacts, with several scholars also with people working outside of chemistry and outside of that has traditionally been considered science, Among these there were people dealing with "cyclical" phenomena or rather phenomena seeming to repeat their features at intervals of years or decades. As we will see later, the contact with American scholar Dewey, who studied socio-economic cycles, was important and pioneering. Dewey quoted Piccardi in his famous work [35].

However, the Piccardi effect and more general fluctuating phenomena did not succeed in "breaking" the international scientific community, so much so that, after his death (1972), not even his closest associates continued his studies, in particular that of performing a daily test on bismuth chloride. Also, a number of organizations founded by him, such as the CUFF (University Floating Phenomena Centre), were dissolved in 1976. Rather, a certain divulgation of his studies began, but this, unfortunately, was not free from serious errors, inaccuracies and misrepresentations.

\section{4. "Bad" Popularizzation}

Piccardi attached very much importance to the popularization of his discoveries and to contact with the mass-media but he did not personally oversee the disclosure of what he had discovered, with the exception of some papers by him, which were mostly informative. Unlucky, the popularization and the discussion of Piccardi's discoveries and views were carried out with serious mistakes both by people thinking the Piccardi effect was a real effect and by people thinking the opposite. A striking example concerns an episode related by Masini that, if real, would have been decisive proof in favor of the Piccardi effect. But Masini discusses the case in two books in two completely different versions and there are large mistakes in each version. In the first version [36] the case happens at a meeting of COSPAR (Committee for Space Research) in 1961. Professor H. C. Friedman, a world authority on space search working at the NRL, is holding a conference in San Diego illustrating a kind of map of the interplanetary magnetic field obtained by some American space probes. There is great satisfaction of the people present with warm applause when suddenly Piccardi appears holding a plastic model of the same fields and a work of his dated six years before. The models of Friedman and Piccardi are exactly alike. There is general surprise, and Friedman asks Piccardi how he got those results. Piccardi answers candidly to have used his "short glasses." In the second version [37], we are ever at meeting of COSPAR in 1961 but now we are in Florence. Friedman talks in the morning and Piccardi talks in the afternoon after lunch. Piccardi explains the results of research of his made six years before with the same numbers as those exhibited by Friedman in his previous communication. Friedman, always wonderful, asks Piccardi more insistently than in the first version where those numbers come from, and Piccardi answers that the numbers come from the observation of simple inorganic reactions. Apart from the significant differences in the two versions, there are two 
serious mistakes that can be found by a simple Google or Wikipedia search. The COSPAR meeting took place in Florence not in 1961 but in 1964, and NRL is not in San Diego but in Washington. Besides, in 1955 or 1956 there were no Piccardi papers related to mapping interplanetary magnetic fields while Professor Friedman showed up in the COSPAR meeting of 1961 in a communication not directly related to the interplanetary magnetic field [38]. This causes one to be astonished and doubtful of the intellectual honesty of Masini, especially as these tales were in books written, for the remaining part, very seriously. However, those who saw in the Piccardi effect a scientific basis of astrology demonstrated little intellectual honesty as well. Piccardi had no contact with astrologists; indeed, the closest collaborators of Piccardi rejected any link between their findings and astrology [39]. However, an article published in the middle of 70s in a well-known Italian magazine (Famiglia Cristiana) (the author has not been able to track down the exact date) speaks rather generally and confusedly on the Piccardi effect and says surely that the effect is a possible scientific basis of astrology. The Piccardi effect was quoted in a well-known book by some supporters of biorhythms as well [40] (and, in this case, there were actually contacts between Piccardi and the authors but no collaboration). But the most striking case of poor divulgation or rather "fraudulent" use of the effect regards homeopathy. This happened even though Piccardi never used homeopathic remedies; he had no professional contact with homeopathy or companies operating in this field, and homeopathy was not cited by Piccard's staff. In 1986, Professor Benveniste published the results of one oif his researches in the journal Nature. claiming to have evidenced a certain " memory of water " which can explain how homeophatics remedies work Then, he promptly was contradicted by subsequent checks, which didn't show the existence of a "memory of water." Homeopaths, from this moment, have not only relied on the "memory" of water as the scientific basis of homeopathy but also cited Piccardi's research, stating that he discovered the memory of water. And here we should have a bit of clarity. Piccardi really believed in his effect and thought electromagnetic radiation operating on the hydrogen bonds of water would create some structures that functioned as a kind of "antenna" for low intensity and low frequency signals, such as interplanetary magnetic fields, and Piccardi believed water, using these "antennas," was able to change some of its chemical/physical properties.

To justify how their preparations have therapeutic efficacy in spite of the very strong dilutions causing only a few atoms or nothing of the active ingredient to be present, homeopaths argued that, during the process of dilution of water, in contact with an active ingredient, the water changes its structure and "remembers" this contact, acquiring medicinal properties. The Piccardi effect and the faith of homeopaths are similar things, but there is a fundamental difference. Having medicinal properties is not a result of being an antenna for the solar magnetic field.

More recently, a similar bad citation of the Piccardi effect occurred and the author was a direct witness of it. In discussion linked to Wikipedia issue "Giorgio Piccardi" Dott. Valeri, who introduced himself as the president of CIFA (International Centre for Research Environmental Factors) and intervened in a discussion, stating, among other things, to have filed a patent for a device working well by applying the Piccardi effect. Intrigued by this statement I wrote him asking for details and the text of the patent arrived on time, but it is a device [41] that purifies water using industrial high electric fields of $100 \mathrm{KV} /$ meter and a frequency range of radio waves of a few hundred $\mathrm{kHz}$ while the Piccardi effect involved electromagnetic fields of very low intensity and whose frequency was well below 1 Hertz.Then, there are those who have criticized Piccardi in an ungenerous and dismissive way, such as the Italian chemical and journalist Silvano Fuso, known for his struggle against pseudoscience. Fuso, in an article, which is actually very short [42], tells about Piccardi as a scientist in his own way, a strange scholar doing experiments that did not involve a lot of sense. However, four years later, Fuso published a longer, much more accurate article [17] in the official journal of the Italian CICAP (Centre for Investigation of Paranormal Claims). In this article, he, reiterating and clarifying criticisms of the way of working of Piccardi, admitted his quality as a scientist and as a man.

\section{A Personal Contribution}

Two years after the publication of the above citied Kauffman paper, two employees of Piccardi [43] wrote an article that can be considered the "sum" of every research on the Piccardi effect. This article contains spectral analyzes made by several but rigorous mathematical methods applied to the whole series of measurements made in Florence by Piccardi from 1951 to 1971 and by Boute in Brussels from 1956 to 1976. They are the results of 20 years of measurements made every day three times a day. Now, as can be seen in chart below taken from that article, there are some evident periodicities. The graphics are numerous because they relate to various types of testing (F, D or P). The graph is this:

In all graphs, there is a clear annual periodicity.This is especially present in the graph relating to D testsncy. A clear periodicity of 11 years (the sunspot cycle) is not obvious while there are two clear periodicities: one of 10 years and another of 12 years

So, also if the solar hypothesis is not confirmed and, in fact, is not mentioned in the article, there are obvious periodicities, which must be explained and which is not compatible with randomly distributed numbers.

The author asked himself, "How can self-deception produce periodicity in the data series?" To try to answer this question, the author has written simple Matlab programs that simulate the effects of Piccardi's measures or rather are a simulation of the measure of the Piccardi effect. First simulation describe results of measures with no real Piccardi effect and but with the self-illusion of the experimenter, which, in the case of sedimentation, always sees greater speed in the activated water, Second simulation is with no Piccardi effect but assuming a periodicity in error, think of Piccardi's employees, some of whom were more "believers" of the effect and others less.

A simulation of the measure of the Piccardi effect made with a real very small physical effect and with the above error, which was non-periodic, was made in the third simulation. 
I list the three programs at bottom of the text.

F-spectrum monthly means precipitation reaction tests

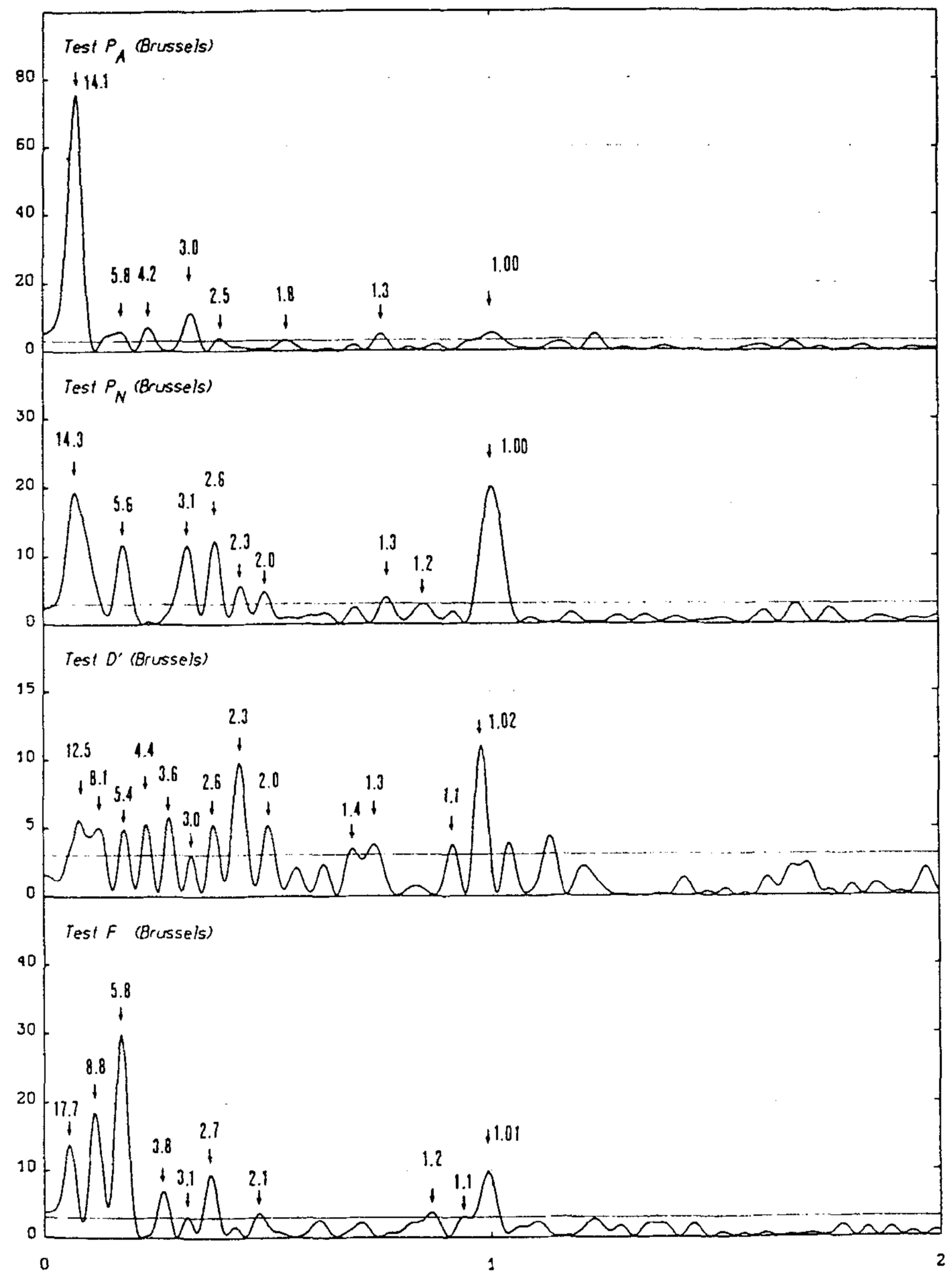

Fig. 3. Time variation in a 20 years periodo of Piccardi tests results. 
Need to explain because it is possible that there is a Piccardi effect. To answer this question, let us consider that, most likely, Piccardi and staff did not always use distilled water as mentioned above. Now it is obvious that tap water is literally full of pollutants, microbes, heavy ions, minerals and substances introduced by man. It is suffice to say that, in the years when Piccardi and Boute made their measures, municipalities periodically put in the water high amounts of chlorine to disinfect the water. So, it is not unreasonable to suppose that the measures of the Piccardi effect have been made on aqueous solutions whose composition varied in a periodic manner. In addition to chlorine, just think how the percentage of pollutants in air and then in water, can vary with annual periodicity, higher in winter with factories open and lower in summer with the factories closed. It cannot be excluded that the radio waves generated by the triboelectricity of mercury used to activate the water produced changes in the aqueous solution by such well known phenomena as electrocoagulation and similar phenomenon.

The obtained data correspond to 1050 weeks ( 25 years each of 42 weeks) and 70 measures each week, 10 each day. The numbers produced by program were subjected to a fast Fourier transforma, and the results are the following graphs:

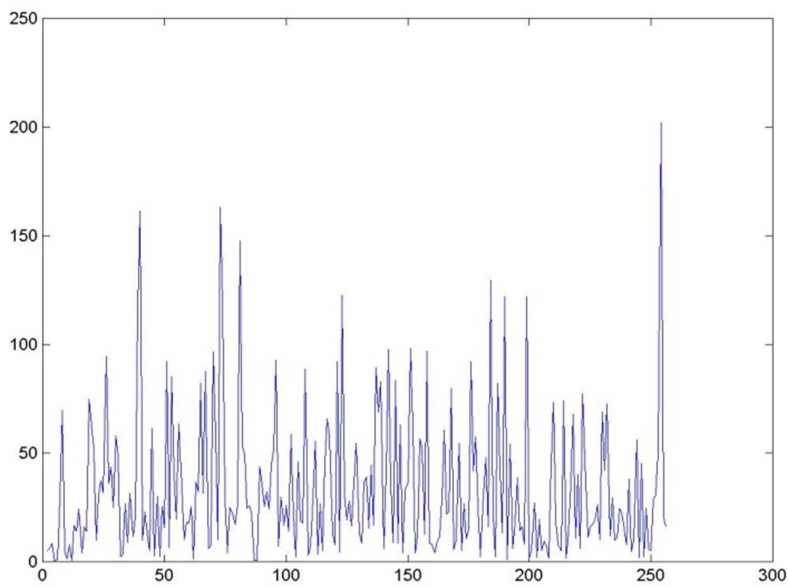

Fig. 4. Results of first simulation (see test).

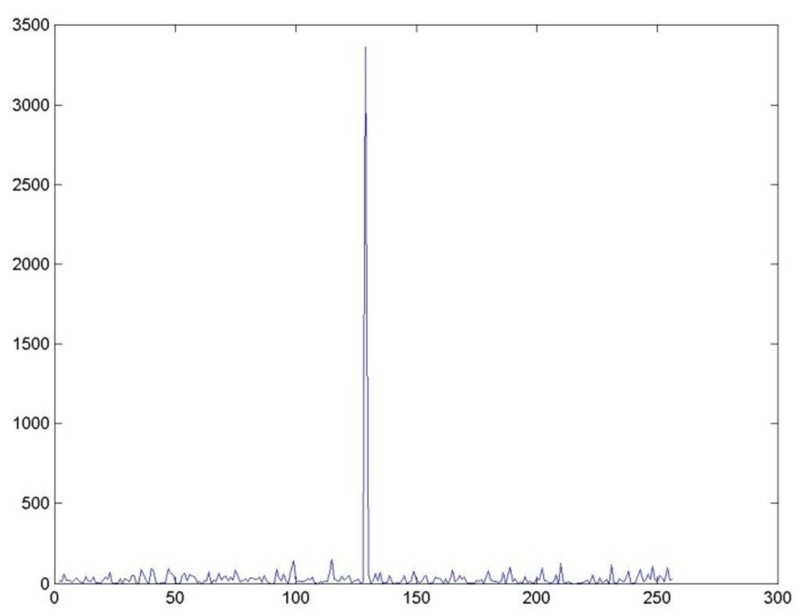

Fig. 5. Aresults of second simulation (see test).

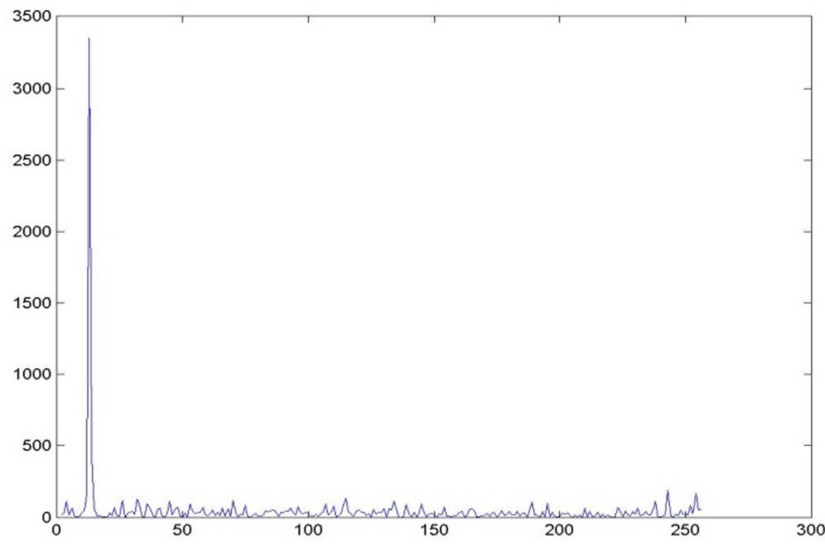

Fig. 6. Aresult of third simulation (see tst).

As you can see, in the first case, there is periodicity, although not so evident as in the figure, but, in the second and in the third case, the periodicity introduced is even more evident than in the graph taken from [43]. So, we can conclude that the self-deception, which is discussed in the article by Kauffman, with small additions, is more than sufficient to explain the Piccardi effect. But, having taught many years in high schools, my personal contribution is not ended here.

Neither supporters nor critics of Piccardi's claim have ever made a test of Piccardi's idea using very weak and very low frequency variable magnetic fields created in a laboratory whose period is variable by the investigator. Very weak magnetic fields can be created in any physics laboratory of a school and it's clear an aqueous solution of bismuth trioxide cannot discern between a sunspot magnetic field and a magnetic field generated by a made-man circuit. It is possible to test Piccardi's hypothesis using the circuit shown in following figure.

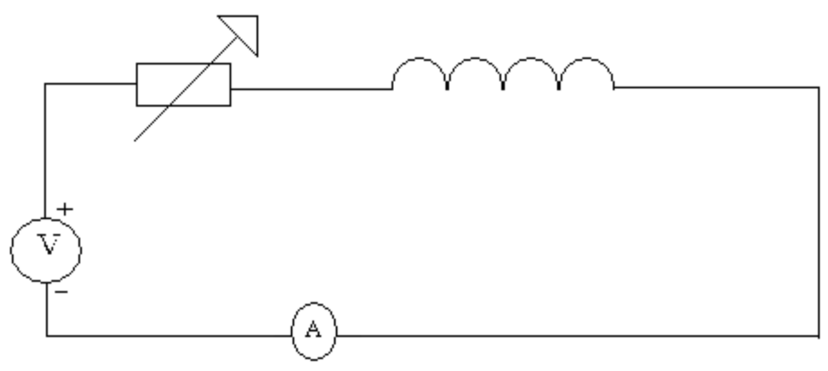

Fig. 7. A schematic vision of circuit used to verify Piccardi effect.

It is a simple circuit with a DC voltage generator, 0-20 Volt, (these and the following numbers are purely indicative) in series with a coil, or still better three or four coils placed in series between them, and a variable resistor plus an amperometre A device similar to a synchronous mixer is buildable in a school too, but it is sufficient to take ten beakers of the stretched dimensions used by Piccardi and to constitute five pairs of them. To activate water it is possible to use a low voltage and low frequency generator, another apparatus available in any laboratory of a school, and to pass the cups of water that you want to activate in front of a coil connected to this generator. We can use tap water or pure water. To simulate 
a weak and very low frequency magnetic field we can suitably vary the value of the voltage given by the generator and/or the resistance. Purely for example, see the table taken from [44] (a magnetic field of a period equal to four hours and thirty minutes is simulated). Obviously, with a similar procedure, magnetic fields with period of days or weeks can be simulated.

Table. 1. Parameters of the experiment to test Piccardi effect described in tst.

\begin{tabular}{llll}
\hline $\begin{array}{l}\text { Now (our } \\
\text { morning) }\end{array}$ & $\begin{array}{l}\text { Voltage } \\
(\mathbf{V})\end{array}$ & $\begin{array}{l}\text { Resistance to }(\mathbf{K} \\
\boldsymbol{\Omega})\end{array}$ & Magnetic field $(\mathbf{m T})$ \\
\hline $8: 30$ & 0 & 100 & 0 \\
$9: 00$ & & 100 & 0.707 \\
$9: 30$ & 10 & 100 & 1 \\
$10: 00$ & & 100 & 0.707 \\
$10: 30$ & 0 & 100 & 0 \\
$11: 00$ & - & 100 & -0707 \\
$11: 30$ & -10 & 100 & -1 \\
$12: 30$ & - & 100 & -0707 \\
$13: 00$ & 0 & 100 & 0 \\
\hline
\end{tabular}

The procedure of experiment is the following:

1) at the times indicated in the table, a person, even a student, turns on the generator and places the rheostat in order to have the resistance value indicated. Simultaneously, another student fills 10 (number is indicative) little glasses with water and activates the water in half of them by passing it beside a coil connected to a low frequency generator

2) the two students place the little glasses in front of the coils, making sure to put them in two rows, one with the glasses with not activated water and the second with the glasses with activated water. However, they must make sure that the glasses with plain water are interposed with the glasses with activated water

3) they put in ossiclorul bismuth, taking all possible precaution to ensure that the same amount of clorul is in the little glasses. The two students, possibly, or others, monitor for a few minutes the formation of the precipitate in the glasses, scoring a point every time the sedimentation speed seems higher in the glass with activated water than in the corresponding glass. Then, water is put away from the glasses and the test is repeated

4) after a time equal to about one-twentieth of the period of the magnetic field, the ratio between the number of points and the number of pairs of short glaess used is calculated (the Piccardi ratio)

After a time equal to two or three times the period of the magnetic field, the values of Piccardi ratios are plotted and, by data analysis software, we look for periodic components of the temporal behavior of the Piccardi ratio, clearly searching for a variability of same period of the applied magnetic field.

The author has done this in [45]. This experience has features differentiating it significantly from classical laboratory experiments and that make it very useful from a didactic point of view. In fact, this experience requires the collaboration of many students, requires a long time for its execution, presents a detachment between the phase of data taking and the phase of analysis and discussion of the same and, in any case, is related to a topic that has been discussed by the scientific community. These are features that make this experiment nearer to a real experiment of particle physics or astrophysics than to classical measures taken at a high school.

\section{Piccardi's Legacy}

Summarizing everything that has been written, it would seem that the scientific heritage of Piccardi does not exist or is negative. An effect being a self-deception, a questionable methodology, especially in terms of the emphasis on qualitative methods, and a kind of New Age vision or forerunner of reality, all indicate the presence of many mistakes in his papers. But if we consider the matter carefully, the scientific heritage of Piccardi presents positive aspects as well, in addition to the remarkable human qualities that no one has questioned.First, there is the strong will to do interdisciplinary research, a will that would lead to confronting and working closely not only with scholars from similar fields, such as chemists and astrophysicists, but also with scholars from disciplines that are completely different from each other, such as physicists and economists. Let us think of the collaboration Piccardi had with Dewey, which took place at the beginning of the 60s, thirty years before the birth of Econophysics, a discipline that applies typical methods of physics to economic studies. An equally striking example of this arises from the article on Etruscan goldsmiths already mentioned. In this article, Piccardi says that, being in Vienna in the home of a friend he knew in that city, there was a jeweler who made jewelry very similar to that made by the Etruscans.

Piccardi spoke with the jeweler personally, comparing his jewels both with those seen in Etruscan museums and with works by other goldsmiths. Piccardi came to the conclusion that the works of this Viennese goldsmith were the most similar that he had seen to those of Etruscans. Then, Piccardi asked this goldsmith to write a description of the procedure and to send it in writing to a specialized journal (Etruscan Studies), which was published in Florence. Piccardi wrote an introduction article with the story that has now been told. And after there was the jewelry one, about which the author can say nothing because the article is written in German.In addition, Piccardi's studies can be considered pioneering for two reasons. First, they are studies on complex and non linear systems where, at least in principle, small perturbations can cause big effects. It's sufficent to see any publications, or abstracts, database such as www.arXiv.org to realize the huge number of works done in this field in last 10 or 20 years.But there is also a more specific reason for considering Piccardi's pioneering studies. Since the 90 s, with the spread of mobile phones (and after of the wireless Internet), there has been a strong interest to highlight the possible non thermal effects of non-ionizing radiations, especially in terms of effects on biological systems. If we think about it, the Piccardi effect could be considered a non-thermal effect of non-ionizing radiation.It seems to the writer that the greatest legacy of Piccardi is in his own intellectual curiosity, in his desire (according to Masini's words) to be more a Renaissance 
intelligence than to be an actual specialist today with the blinders of many scholars, without forgetting the great human qualities of Piccardi that seem summarized very well by the sentences that he said at the end of the first lesson of his course in Physical Chemistry [46]:

"But remember that life I s not just science. Let us never be one-dimensional people. Let us rejoice in art, in world of the poetry, in music, in the theater. Let us do some nice trips to discover the world and then not forget that women are the most beautiful invention of Mother Nature."

I believe that these phrases are the best conclusion of this article of mine on Giorgio Piccardi.

\section{Text of Matlab Programs Used}

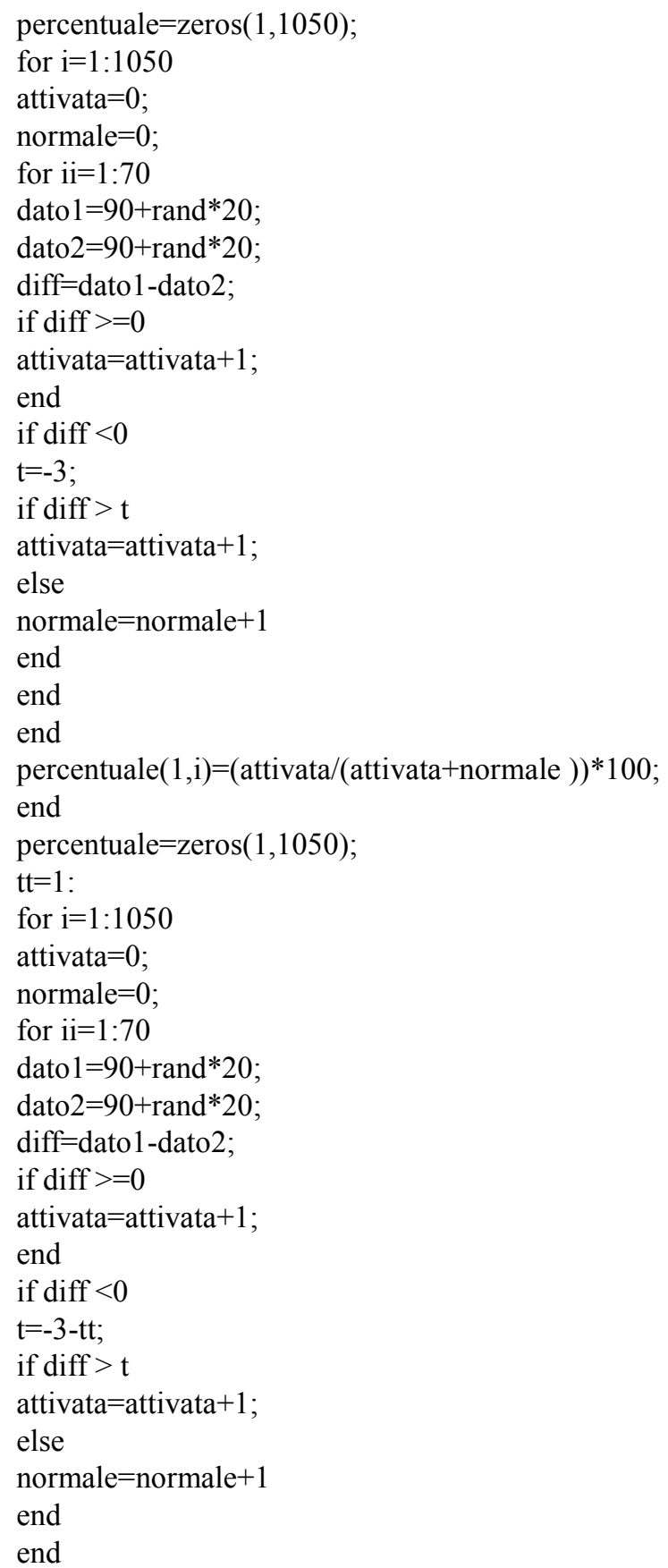


[10] G. Gamow" L'energia atomica”, Milano, Mondadori, 1950, pag 167.

[11] F the full list of Piccaqrdi's paper is in pag.124 of Manzelli, Masini, Costa, I segreti dell'acqua (The secrets of water), Di Renzo press, 1994. pag.. 102 and following.

[12] http://www.treccani.it/enciclopedia/triboelettricita/.

[13] Apart biographies a description of tes can be found in G.Piccardi" Sopra un test inorganico per lo studio degli influssi atmosferici e cosmici", Geofisica e meteorologia, Vol. 3, 4,p.31,1955.

[14] Detailed in G. Piccardi" phenomenes astrophysiques et evenements terrestres", Universite de Paris, p. 12, 1960.

[15] The full list of Piccaqrdi's paper is in pag.124 of Manzelli, Masini, Costa, I segreti dell'acqua (The secrets of water), Di Renzo press, 1994. pag.109 and following.

[16] The full list of Piccaqrdi's paper is in pag.124 of Manzelli, Masini, Costa, I segreti dell'acqua (The secrets of water), Di Renzo press, 1994. page 207.

[17] Let see S.Fuso "Il chimico del Sole", Scienza e paranormale, Vol.47, nr.2, pag 110, 2007.

[18] The full list of Piccaqrdi's paper is in pag.124 of Manzelli, Masini, Costa, I segreti dell'acqua (The secrets of water), Di Renzo press, 1994. pag. 59.

[19] Detailed in G. Piccardi" phenomenes astrophysiques et evenements terrestres", Universite de Paris, p. 12, 1960 or in G.Piccardi," Variazioni dei test D ed attività solare", Geofisica e meteorologia, Vol.6,pag.19, 1958.

[20] The full list of Piccaqrdi's paper is in pag.124 of Manzelli, Masini, Costa, I segreti dell'acqua (The secrets of water), Di Renzo press, 1994. pag.110.

[21] G.Piccardi," Una ipotesi solare", Rendiconto Accademia dei Lincei,Vol. 21, 14, pag.84, 1956.

[22] The full list of Piccaqrdi's paper is in pag.124 of Manzelli, Masini, Costa, I segreti dell'acqua (The secrets of water), Di Renzo press, 1994. pag. 90.

[23] Benveniste" Human basophil degranulation triggered by very dilute antiserum against IgE" Natiure, vol. 333, 2, pag. 816$818,1988$.

[24] http://biblioteca.imss.fi.it/acquisti/miscellanee_piccardi.pdf7.

[25] The full list of Piccaqrdi's paper is in pag.124 of Manzelli, Masini, Costa, I segreti dell'acqua (The secrets of water), Di Renzo press, 1994. pag. 75 or S.Fuso "Il chimico del Sole", Scienza e paranormale, Vol.47, nr.2, 2007. pag. 48.

[26] The full list of Piccaqrdi's paper is in pag.124 of Manzelli, Masini, Costa, I segreti dell'acqua (The secrets of water), Di Renzo press, 1994. part written by Manzelli.

[27] G. Masini, I ricercatori del cielo, Editrice 1 Sorgente, 1975, pag.27.
[28] Dcarlucci, A.. Castaldo, Un paese di baroni, Chiarelettere, 2009.

[29] G. Palermo, utori, Baroni e portaborse. I rapporti di potere nell'università,Editori Internazionali Riuniti, 2009.

[30] G. Piccardt, G. Masini "The test chemical in the auroral zone", Geofisica e Metereologia, Vol 9, 2, p.37, 1969.

[31] G. Masini, I ricercatori del cielo”, Editore la Sorgente, p. 28, 1975.

[32] P. Silvestroni, Fondamenti di Chimica, Veschi Publishers, 1980, p. 572.

[33] Kauffman, Beck "The self deception in science: the curious case of Giorgio Piccardi", Speculation in Science and Technology Vol 10, 4, pag 113, 1986.

[34] The full list of Piccaqrdi's paper is in pag..124 of Manzelli, Masini, Costa, I segreti dell'acqua (The secrets of water), Di Renzo press, 1994. p. 89.

[35] E. R. Dewey, Cycles that Trigger Mysterious Force Events, New York, Manor book 1973.

[36] G. Masini, I ricercatori del cielo", Editore la Sorgente, pp. 31-32, 1975.

[37] The full list of Piccaqrdi's paper is in pag.124 of Manzelli, Masini, Costa, I segreti dell'acqua (The secrets of water), Di Renzo press, 1994. p. 101.

[38] H. C. Friedman "A survey of NRL rocket research results since the last meeting of COSPAR Space Research", pp. 1021-1035, 1961.

[39] The full list of Piccaqrdi's paper is in pag.124 of Manzelli, Masini, Costa, I segreti dell'acqua (The secrets of water), Di Renzo press, 1994. p. 83.

[40] M. Gauqelin, Biological Clocks, Coll. Marabount Universitè, 1973.

[41] V. Gualtieri "fenomeni associati all'attivazione dell'acqua", II International Conference on Bionics Applied and Biophysics, Kiev, Ukraine, 2013.

[42] S. Fuso " Giorgo Piccardi uno scienziato a modo suo ( Giorgio Piccardi A scientist in his own way)”, Le Scienze, Aprile 2003, pag 200.

[43] F. De Meyer, C. Capel-Boute "Statistical analysis of chemical tests by Piccardi", Int. J. Biometeor, Vol. 31, 6, pp. 301-322, 1987.

[44] C. Artemi, " Ricerca a scuola” La Didattica delle scienze, La Scuola press, April 2007.

[45] C. Artemi," From a scientific error, a teaching proposal", SIF Communication Congress 2014.

[46] The full list of Piccaqrdi's paper is in pag.124 of Manzelli, Masini, Costa, I segreti dell'acqua (The secrets of water), Di Renzo press, 1994. p. 105. 